\title{
Effect of Deposition Time on Structural and Optoelectronic Properties of Flower-Like Nanostructured PbS Thin Films
}

\author{
N. H. Sheeba ${ }^{*}$, A. Namitha ${ }^{2}$, K. M. Ramsiya ${ }^{2}$, T. M. Ashitha ${ }^{3}$, R. Suhail ${ }^{3}$ \\ ${ }^{1}$ Department of Physics, M. E. S. Asmabi College, P. Vemballur, Kodungallur, 680671, India \\ ${ }^{2}$ Department of Physics, S. N. College, Nattika, Thriprayar, 680566, India \\ ${ }^{3}$ Department of Physics, M. E. S. Marampally College, Aluva, 683547, India
}

Received 25 May 2020, accepted in final revised form 28 September 2020

\begin{abstract}
Polycrystalline nanostructured $\mathrm{PbS}$ thin films are deposited onto soda-lime glass substrates by the method of chemical bath deposition (CBD) at different duration of deposition time. The structure and surface morphology of the films are characterized by X-ray diffraction (XRD) and field effect scanning electron microscopy (FE-SEM). XRD pattern exhibits polycrystalline structure with preferential orientation along (200) direction, parameters such as crystallite size, lattice constant, lattice-strain and dislocation density are calculated. The FE-SEM images show appearance of flower like structure on formation of PbS films which is indicative of suitability in gas sensing applications. Studies on optical properties carried out by UV-Vis spectroscopy measurements show bandgap in the range $1.65 \mathrm{eV}-1.41 \mathrm{eV}$. The photoluminescence spectra of the films exhibit two peaks centered at around $613 \mathrm{~nm}$ and $738 \mathrm{~nm}$ after excitation at $450 \mathrm{~nm}$. Electrical studies from Hall measurements indicate the carrier concentration and mobility of the $\mathrm{PbS}$ samples corroborate the variations in the conductivity.
\end{abstract}

Keywords: Thin films; Chemical synthesis; Crystal growth; Surface morphology; Hall effect.

(C) 2021 JSR Publications. ISSN: 2070-0237 (Print); 2070-0245 (Online). All rights reserved. doi: http://dx.doi.org/10.3329/jsr.v13i1.47240 J. Sci. Res. 13 (1), 9-20 (2021)

\section{Introduction}

Lead sulphide $(\mathrm{PbS})$ belongs to binary IV-VI semiconductor material with direct narrow optical energy band gap which can be tuned between $0.41 \mathrm{eV}$ to $3 \mathrm{eV}$ at $300 \mathrm{~K}$ [1]. The flexibility to vary the band gap in $\mathrm{PbS}$ makes it a better candidate in solar cell applications [2]. Further, it is one of the oldest and most common detection materials in various infrared detectors. It functions as a photon detector, responding directly to the photons of radiation, as opposed to thermal detectors $[3,4]$. The large Bohr radius of $18 \mathrm{~nm}$ of the material leads to the observation of quantum confinement effects, a desirable property in

\footnotetext{
Corresponding author: sheebames.naser@gmail.com
} 
the field of Dye Sensitized Solar Cells (DSSC) [5]. By many years, there has been an increasing interest in the development of semiconductor gas sensors to their advantageous features such as low cost, high sensitivity, fast response/recovery time, and simplicity in device structure and circuitry [6,7]. There are few reports of PbS gas sensors which can work at moderate operating temperatures unlike commonly used metal oxide gas sensors in the range 200 to $650{ }^{\circ} \mathrm{C}$ as their operating temperatures [8,9]. It is well known that among different preparation techniques such as SILAR [10], Sputtering [11], Spray Pyrolysis [12] etc. the method of chemical bath deposition (CBD) is the most inexpensive technique for $\mathrm{PbS}$ thin films which is based on the reaction of the species on the substrate surface from aqueous solutions [13,14].

Even though $\mathrm{PbS}$ is a widely investigated material due to its varied applications, the field of gas sensors is a less explored area [15-17]. The desired characteristic of a thin film as a gas sensor is the roughness of the surface with large surface area. Such a surface can provide adsorption sites by oxygen vacancies trapped within the surface which is conducive to good sensor performance [18]. In this work, we present the morphology evolution of $\mathrm{PbS}$ thin films with deposition time to form a surface with flower-like structure using the cost effective method of Chemical Bath Deposition technique (CBD). Further, the essential requisite of a sensor material need to be balanced with the processing costs for practical applications. There are many reports of chemically synthesized $\mathrm{PbS}$ thin films with characterization of their significant properties $[19,20]$. But to the best of our knowledge, $\mathrm{PbS}$ thin films with a morphology of flower-like structure is rarely reported. The present work aims to study the micro-structure, surface morphology, optical characteristics, photoluminescence and electrical parameters of $\mathrm{PbS}$ thin films indicating the suitability of the material in gas sensor applications based on its surface morphology and as absorber material in DSSC.

\section{Experimental}

Pure $\mathrm{PbS}$ thin films are grown on cleaned soda lime glass substrates via chemical bath deposition technique. The chemicals used for the preparation of $\mathrm{PbS}$ thin films consist of lead acetate $\left[\mathrm{Pb}\left(\mathrm{CH}_{3} \mathrm{COO}\right)_{2} \cdot 3 \mathrm{H}_{2} \mathrm{O}\right]$ (Merck, India), thiourea $\left[\left(\mathrm{H}_{2} \mathrm{~N}\right)_{2} \mathrm{CS}\right]$, sodium hydroxide $(\mathrm{NaOH}$, Merck, India) and triethylene amine (TEA). The reagents are of analytical grade and used without further purification. The precursor solution consists of $3.5 \mathrm{~mL} 2 \mathrm{M} \mathrm{NaOH}, 3.0 \mathrm{~mL}$ of $1 \mathrm{M}$ thiourea and $2.5 \mathrm{~mL}$ of $0.5 \mathrm{M}$ lead acetate together diluted to $50 \mathrm{~mL}$ with two drops of TEA. Cleaned glass substrates are then inserted vertically into the beaker at different dipping times such as 1, 3 and $6 \mathrm{~h}$, respectively. For the convenience of discussion, the as-prepared $\mathrm{PbS}$ films are designated as $\mathrm{PbS}-1, \mathrm{PbS}-2$ and $\mathrm{PbS}-3$ corresponding to the deposition times. The reaction process for forming $\mathrm{PbS}$ films is described elsewhere [21].

The structural properties of the as-prepared $\mathrm{PbS}$ films are investigated using $\mathrm{X}$-ray diffraction, XRD (Bruker AXS D8 (USA) Advance X-ray diffractometer with $\mathrm{Cu} \mathrm{K}_{\alpha}$ radiation $\lambda_{\mathrm{Cu}}=0.154056 \mathrm{~nm}$ as the source) and surface morphology using Field Effect 
Scanning Electron Microscope, FE-SEM (Sigma 300 HV FESEM, Germany). The optical transmittance and absorbance have been recorded by Model: Varian, Cary $5000 \mathrm{UV}-\mathrm{Vis}$ spectrophotometer, (Australia). Photoluminescence spectra of $\mathrm{PbS}$ samples are recorded using Model: Fluoromax-4C spectro-fluorometer (Japan) with the excitation wavelength of $450 \mathrm{~nm}$. The Hall measurements have been carried out by four-probe method at room temperature using ECOPIA Hall effect measurement system (HMS-3000 Ecopia, South Korea) in a magnetic field strength of $0.54 \mathrm{~T}$.

\section{Results and Discussion}

\subsection{Structural characterization}

The XRD spectra of the as-prepared $\mathrm{PbS}$ nano crystalline thin films at different growth time are shown in Fig. 1. All the synthesized $\mathrm{PbS}$ thin films have cubic rock salt $(\mathrm{NaCl})$ type structure (JCPDS cards No. 1-880) and the patterns contain peaks that are clearly distinguishable. In the sample $\mathrm{PbS}-1$, the diffraction peaks are observed at angles around $26^{\circ}, 30^{\circ}, 43^{\circ}, 51^{\circ}$ and $53^{\circ}$ that correspond to the (111), (200), (220), (311) and (222) planes of cubic $\mathrm{PbS}$ as confirmed by standard card with an extra peak at $34^{\circ}$. This corresponds to peak of lead sulphate $\left(\mathrm{PbSO}_{4}\right)$ (JCPDS 82-1855) which indicates the formation of $\mathrm{PbS}$ is incomplete at this stage of deposition. In $\mathrm{PbS}-2$ this diffraction peak vanishes, retaining all the peaks corresponding to $\mathrm{PbS}$ and the intensity is found slightly increased from that of $\mathrm{PbS}-1$. The sample $\mathrm{PbS}-3$ display characteristic $\mathrm{PbS}$ peaks with higher intensity which is indicative of improved crystalline structure [22,23]. Moreover, the absence of any other peaks corresponding to metallic clusters or impurities supports the quality of samples [18]. All PbS films exhibit preferential orientation along (200) direction. Table 1 illustrates the crystallite size of the $\mathrm{PbS}$ samples which is not affected appreciably with growth time. The average crystallite size is calculated using well-known Scherrer formula [24].

$\mathrm{D}=\frac{0.9 \lambda}{\beta \cos \theta}$

where $\lambda$ is the wavelength used $(0.154 \mathrm{~nm}), \quad \beta$ is the angular line width at half maximum intensity and $\theta$ the Bragg angle.

The PbS-2 sample exhibits a small decrease in crystallite size, but as dip time increases a tendency for growth in crystallite size is noticed. This must be due to the effect of increase in thickness after the formation of pure $\mathrm{PbS}$ crystals. The dislocation density which is a measure of number of dislocation lines per unit volume has been calculated using equation [22].

$\delta=\frac{1}{D^{2}}$ 
For all samples, the variation of $\boldsymbol{\delta}$ is in accordance with that in crystallite size. The lattice constant ' $a$ ' of the cubic rock salt has been computed for each peak using the formula [11].

$a=d \sqrt{h^{2}+k^{2}+l^{2}}$

where $h, k$ and $l$ are Miller indices and $d$ the inter-lattice spacing. In order to obtain more accurate value of lattice constants free from all systematic errors, the iterative technique of Nelson- Riley plots are employed. These are plots of the error function versus calculated values of lattice constant for different planes. The corrected values of lattice constant ' $a$ ' is estimated from Nelson-Riley plots of ' $a$ ' versus error function $f(\theta)$ [25]. The extrapolation to $\theta=90^{\circ}$ extracts the correct value of lattice constant ' $a$ '.

$f(\theta)=\frac{1}{2}\left[\frac{\cos ^{2} \theta}{\sin \theta}+\frac{\cos ^{2} \theta}{\theta}\right]$

Fig. 2 depicts Nelson-Riley plots for pure PbS samples PbS-2 and PbS-3 and the value of lattice constant ' $a$ ' indicate that it is improved and approaches the bulk value of 5.936 $\left(\mathrm{A}^{\circ}\right)$ when deposition time increased from $3 \mathrm{~h}$ to $6 \mathrm{~h}[10,13]$. But the deviation from the bulk value suggests that the films are strained [26].

The lattice strain is calculated from the prominent peak using the relation [22]:

$\varepsilon=\frac{\beta \cos \theta}{4}$

The values of strain illustrated in Table 1 indicate that on the formation $\mathrm{PbS}$ crystals, strain decreases with increase in dip time which reflects relaxation of thicker films. In the present work, among the samples, PbS-2 exhibits increase in dislocation density as the particle size decreases which leads to strain-hardening. This implies that lattice strain in $\mathrm{PbS}-2$ film restricts the increase in particle size at the grain boundaries. Meanwhile the lower value of strain and high intensity in diffraction pattern for PbS-3 is indicative of the increased thickness with deposition time which comes in agreement with reported results $[22,25]$.

\subsection{Surface morphology}

The morphology of nano crystalline $\mathrm{PbS}$ thin film has been investigated using FE-SEM which is shown in Fig. 3. It has been observed that the sample PbS-1 formed at a growth time of $1 \mathrm{~h}$ possesses a surface with uniform grains, but has some voids and small cracks. As from the XRD data of the sample, the formation of PbS thin film is incomplete at this deposition time. A close observation of the image indicates the tendency to the formation of flake like structure while the samples PbS-2 and PbS-3 illustrate surfaces with thickly covered particles in the form of flakes and protruding flower like structure. The diffraction peaks illustrate that at this deposition time the samples PbS-2 and PbS-3 represent pure $\mathrm{PbS}$ material. Even though the formation of flower like structure is characteristic of this 
preparation technique, the highlighting factor in this study is, the flower like structure have been rarely reported in the case of $\mathrm{PbS}$ thin films. There are reports of surface images of $\mathrm{PbS}$ thin films with granular structures of well -defined grain boundary $[15,16]$. The petal-to-petal size of the flowers is found to be slightly increased by increasing the deposition time. The agglomerated particle size of the sample PbS-1 is found to be $\sim 117$ $\mathrm{nm}$ while petal-to-petal size of the flowers of PbS-2 and PbS-3 found to be $\sim 261 \mathrm{~nm}$ and $\sim 314 \mathrm{~nm}$ respectively. It is reported that relatively rough surface of the sample supports increased gas adsorption and in the present samples the flower like structure obviously provides large surface area which is a necessary requirement for the application of the film in the field of gas sensors [7-9].

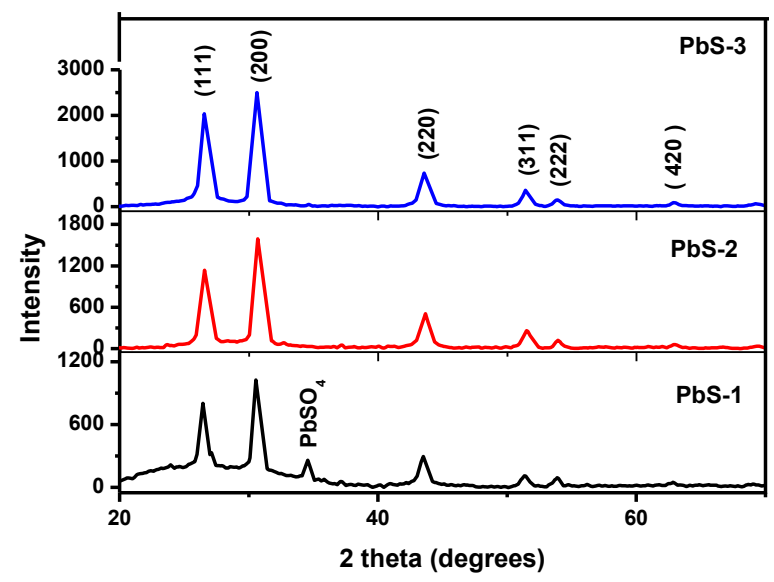

Fig. 1. XRD pattern of as-prepared $\mathrm{PbS}$ thin films at different deposition time.
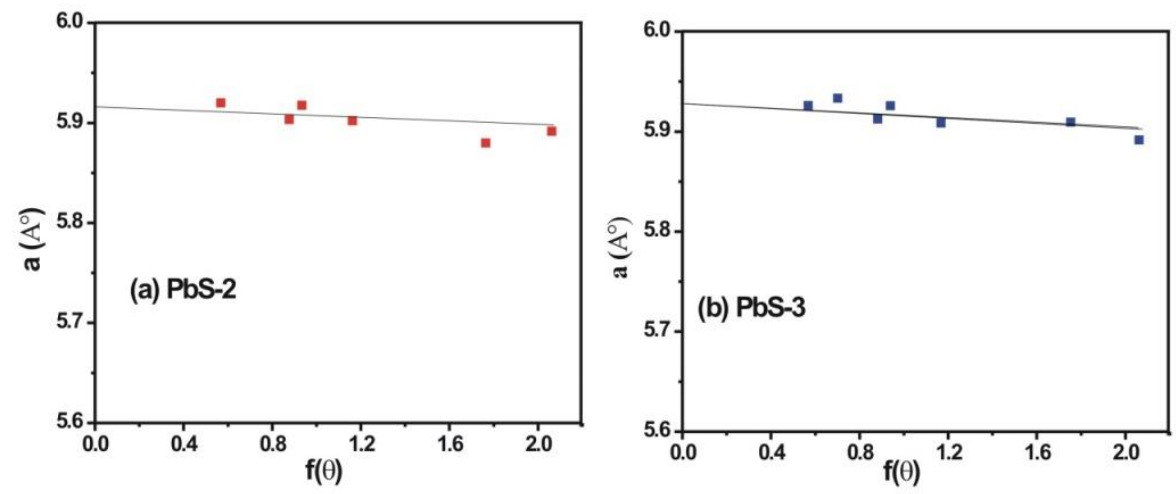

Fig. 2. Nelson-Riley plots of (a) PbS-2 and (b) PbS-3 samples. 
Table 1. Comparison of crystallographic data for as-prepared $\mathrm{PbS}$ thin films.

\begin{tabular}{ccccc}
\hline Sample & $\begin{array}{c}\text { Crystallite size } \\
\mathrm{D}(\mathrm{nm})\end{array}$ & $\begin{array}{c}\text { Dislocation density } \\
\boldsymbol{\delta} \times 10^{15}\left(\mathrm{~m}^{-2}\right)\end{array}$ & $\begin{array}{c}\text { Lattice parameter } \\
\mathrm{a}\left(\mathrm{A}^{\circ}\right)\end{array}$ & Strain $\boldsymbol{\varepsilon \times 1 0 ^ { - 3 }}$ \\
\hline $\mathrm{PbS}-1$ & 21 & 2.3 & - & 1.66 \\
$\mathrm{PbS}-2$ & 18 & 3.1 & 5.92 & 1.94 \\
$\mathrm{PbS}-3$ & 21 & 2.3 & 5.93 & 1.68 \\
\hline
\end{tabular}

The formation of flower-like structure can be elucidated based on the growth kinetics. Prolonged deposition time leads to increase in density of grains. On the thermodynamics point of view, the surface growth shows the tendency to maintain the surface energy to the minimum. In the present case, as deposition time increases, the larger number of grains formed are likely to aggregate and form flakes as illustrated by FE-SEM. Further, the neighbouring flakes agglomerate and self- assemble to form flower like structure to have minimum surface energy by reducing the exposed areas. The $\mathrm{PbS}$ samples exhibit a gradual evolution of morphology leading to the formation of flower-like structure as deposition time increases from $1 \mathrm{~h}$ to $6 \mathrm{~h}$. From diffraction pattern of the samples, it is possible to infer that $\mathrm{PbS}$ flowers grow along (200) plane [27,28].
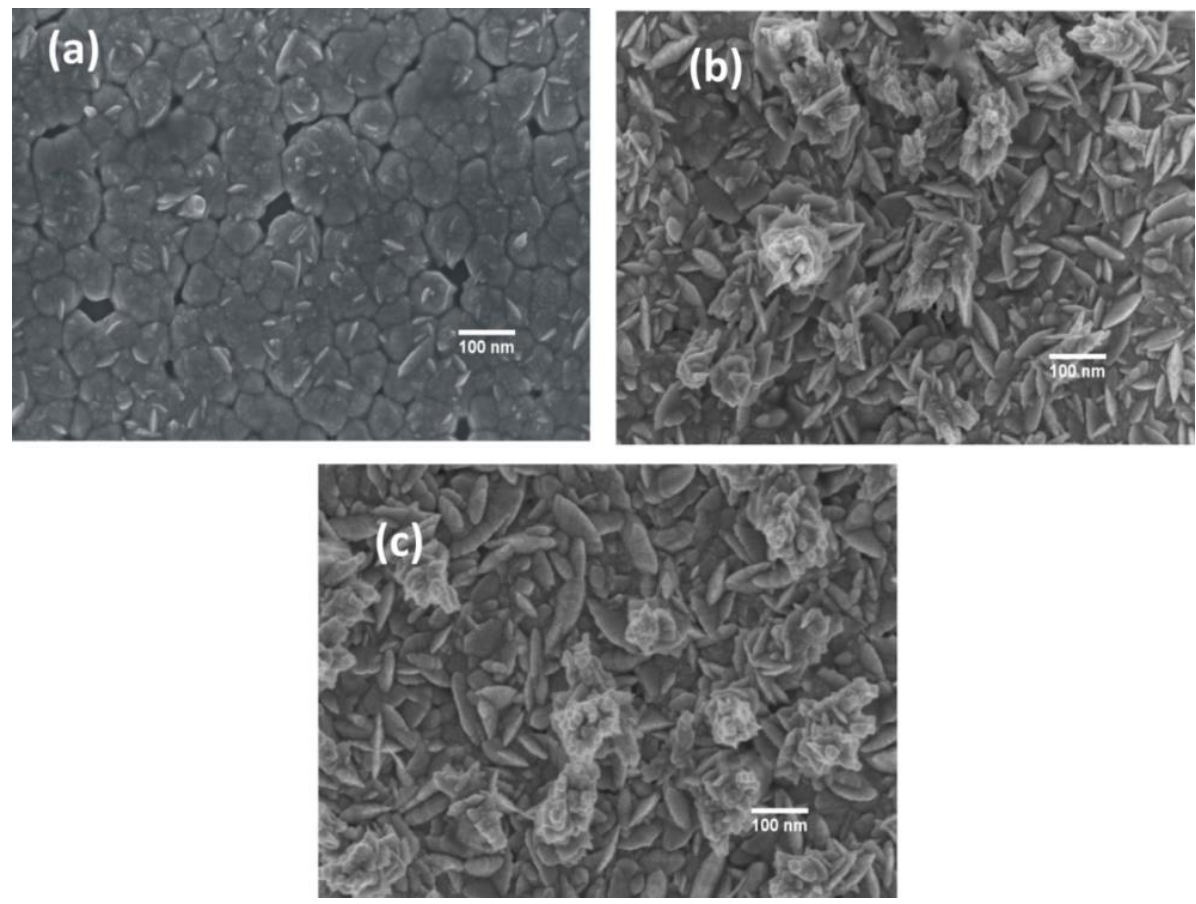

Fig. 3. FE-SEM micrographs of as-deposited PbS samples (a) PbS-1 (b) PbS-2 (c) PbS-3. 


\subsection{Optical studies}

The transmittance spectra of the as-prepared PbS samples illustrated in Fig. 4 indicate that the transparency deteriorates as the deposition time increases. From the figure it is clear that for all samples in the visible region of $400-700 \mathrm{~nm}$ the transmittance is very low, obviously high absorbance is exhibited by the films [23]. The surface of the film appeared darker as the deposition time increased from samples PbS-1 to PbS-3.

The optical absorption of the PbS samples is recorded in the range 200 to $1500 \mathrm{~nm}$ and optical band gap energy has been calculated from Tauc's plot. As a direct band gap material, the film under study has an absorption coefficient $\alpha$ obeying the following relation for high photon energies $h v$

$\alpha h \vartheta=A \sqrt{\left(h \vartheta-E_{g}\right)}$

Where $E_{g}$ is the band gap of the $\mathrm{PbS}$ films and $A$ is a constant [13]. The variation of $(\alpha h v)^{2}$ with $h v$ is linear at the absorption edge which illustrates the direct band gap nature of $\mathrm{PbS}$ semiconductor. The optical band gaps of as-prepared $\mathrm{PbS}$ samples formed at $1 \mathrm{~h}(\mathrm{PbS}-1)$, $3 \mathrm{~h}(\mathrm{PbS}-2)$ and $6 \mathrm{~h}(\mathrm{PbS}-3)$ are estimated using UV-Vis spectrum and found to be 1.65 , 1.64 and $1.41 \mathrm{eV}$ respectively as shown in Fig. 4. It is observed that as deposition time increases optical band gap is reduced even though variation is not noticeable. The observed bandgap is in agreement with reported values [25,29].
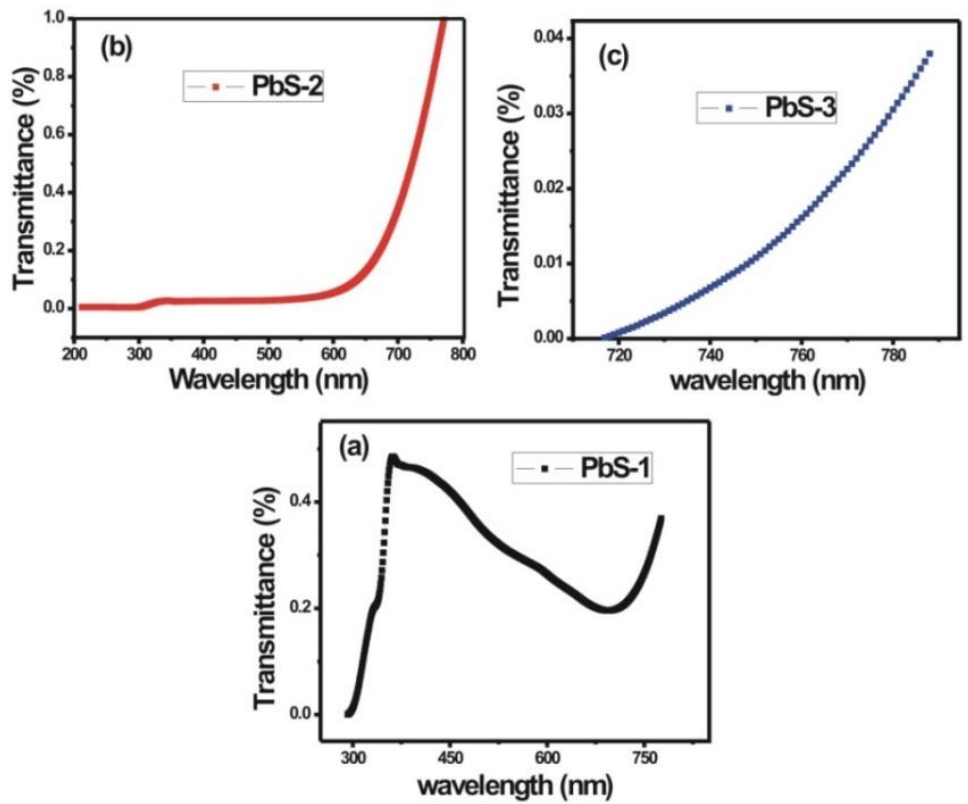

Fig. 4. Transmittance spectra of as-prepared PbS samples. 


\section{Photoluminescence}

The room temperature photoluminescence emission spectra of nano-crystalline samples $\mathrm{PbS}-1, \mathrm{PbS}-2$ and PbS-3 at three different growth times are illustrated in Fig. 5. The sample PbS-1 with $1 \mathrm{~h}$ growth time exhibits low intense PL peaks at 448 and $464 \mathrm{~nm}$. Similar observation has been reported by Rajathi et al and according to them the peaks are due to the transitions in nano-crystalline $\mathrm{PbS}$ lattice [30]. But the samples PbS-2 and PbS3 show emergence of emission peaks at 613 and $737 \mathrm{~nm}$ at the same excitation of $450 \mathrm{~nm}$. Singh et al [31] have reported that the shorter wavelength emission is ascribed to a direct recombination and the longer wavelength to combination through shallow surface states. It is well known that $\mathrm{PbS}$ is weakly luminescent at room temperature. It has a narrow band and exceptionally large exciting Bohr radius $(18 \mathrm{~nm})$, which makes it susceptible to charge carrier quantum confinement effects. These features of $\mathrm{PbS}$ nano-crystals prevent them from producing high yield of PL, as most of the energy is lost through non-radiative processes. However, the low emission peak at $613 \mathrm{~nm}$ may be attributed to quantum confinement effect in our samples. As reported by researchers, it is caused by localization of electrons and holes in a confined space resulting in observable quantization of the energy levels of the electrons and holes [21,32].

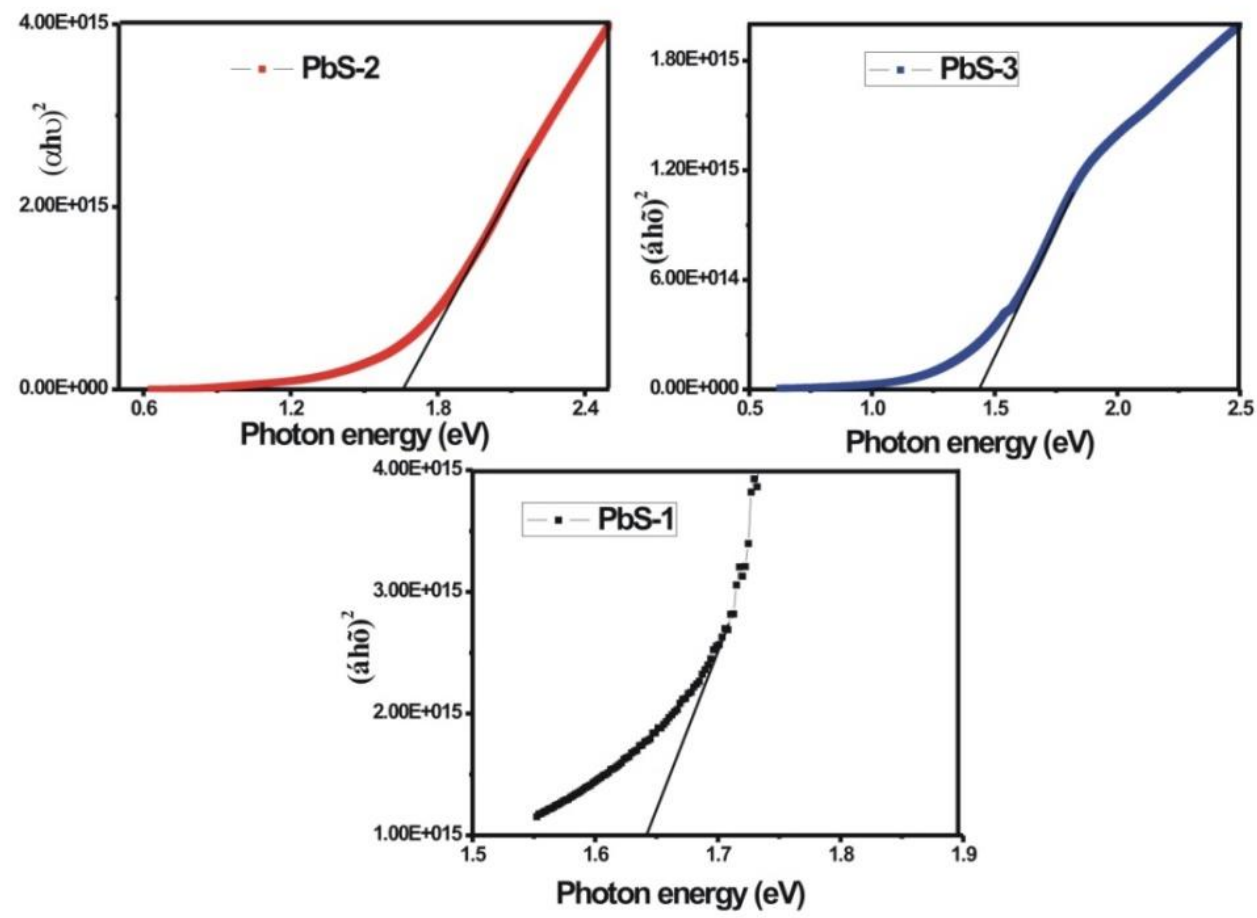

Fig. 5. Tauc's plot illustrating optical bandgap of as-prepared PbS samples. 

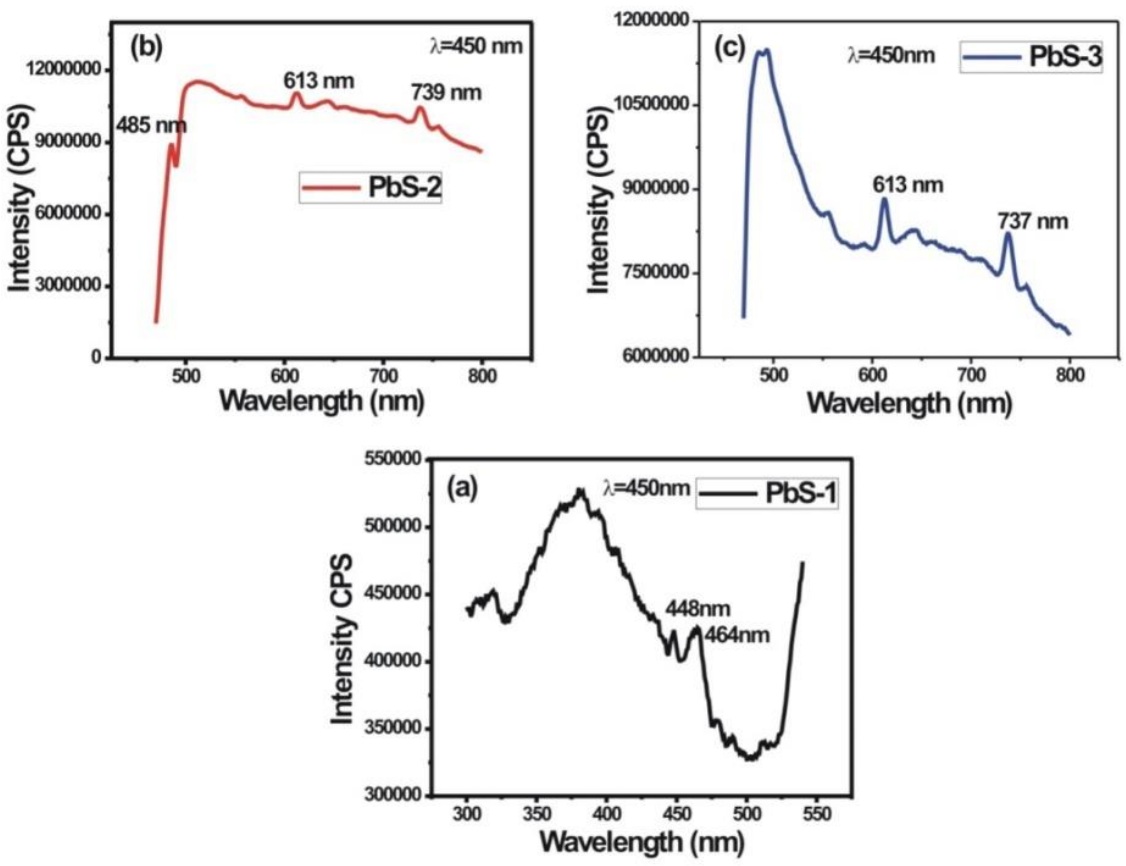

Fig. 6. Room temperature PL spectra of as-prepared PbS samples.

\subsection{Electrical properties}

The Table 2 depicts room temperature Hall measurement data such as resistivity $(\rho)$, conductivity $(\sigma)$, mobility $(\mu)$ and carrier concentration $(n)$ of as-prepared $\mathrm{PbS}$ thin films. From Hall measurements it is found that the room temperature conductivity of $\mathrm{PbS}$ thin films increases with increase in the deposition time. The table shows the conductivity of the sample PbS-2 prepared at $3 \mathrm{~h}$ duration is enhanced by one order from the sample $\mathrm{PbS}$ 1 , but on further increasing the growth time no noticeable change in conductivity is observed. The carrier concentration of the films increased as the growth time increased from $1 \mathrm{~h}$ to $3 \mathrm{~h}$ while only a slight increase observed when the dip time increased to $6 \mathrm{~h}$. This may be due to the attainment of saturation in crystal formation $[3,33]$. Further, even with increased carrier concentration, the sample PbS-3 exhibits improved mobility which comes in agreement with better conductivity. This may be attributed to the fact that for the sample, larger grain size reduces the grain boundary scattering leading to reduction in resistivity [34,35]. 
Table 2. Hall measurement data of as-prepared $\mathrm{PbS}$ thin films.

\begin{tabular}{ccccc}
\hline Sample & $\begin{array}{c}\text { Resistivity } \rho \\
(\Omega-\mathrm{cm})\end{array}$ & $\begin{array}{c}\text { Conductivity } \sigma \\
(\mathrm{S} / \mathrm{cm})\end{array}$ & $\begin{array}{c}\text { Mobility } \mu \\
\left(\mathrm{cm}^{2} / \mathrm{Vs}\right)\end{array}$ & $\begin{array}{c}\text { Carrier concentration } \\
\mathrm{n}\left(/ \mathrm{cm}^{3}\right)\end{array}$ \\
\hline $\mathrm{PbS}-1$ & 9.02 & 0.11 & 33.5 & $2.04 \times 10^{16}$ \\
$\mathrm{PbS} \mathrm{-2}$ & 0.489 & 2.04 & 69.8 & $1.82 \times 10^{17}$ \\
$\mathrm{PbS} \mathrm{-3}$ & 0.124 & 8.01 & 77.9 & $6.39 \times 10^{17}$ \\
\hline
\end{tabular}

\section{Conclusion}

The effect of deposition time on structural, morphological, optical and electrical properties of chemically deposited $\mathrm{PbS}$ thin films are investigated. The XRD studies reveal the evolution of pure $\mathrm{PbS}$ samples with the face centered cubic structure at a deposition time of $3 \mathrm{~h}$. The FE-SEM micrographs show the formation of flower like structure leading to suitability of the films in the field of gas sensor applications. Optical studies indicate a slight decrease in bandgap energy with increase in deposition time which is in the range $1.65-1.41 \mathrm{eV}$. Even though $\mathrm{PbS}$ is weakly luminescent, the photoluminescence spectra of the as-prepared $\mathrm{PbS}$ films show two peaks centered around 613 and $739 \mathrm{~nm}$ after excitation at $450 \mathrm{~nm}$. Room temperature Hall measurements and hot probe technique reveal that all samples have p-type conductivity. The three $\mathrm{PbS}$ samples in this study exhibit similar pattern of variations with different properties discussed which clearly indicate that complete formation of $\mathrm{PbS}$ takes place in sample $\mathrm{PbS}-2$ at a growth time of $3 \mathrm{~h}$. On further increasing the dip time to $6 \mathrm{~h}$, very slight improvement in the quality of films is observed. Hence PbS-2 that grown at $3 \mathrm{~h}$ dip time is opted as the suitable sample with the most inexpensive preparation technique which would find applications in the field of gas sensors and dye-sensitized solar cells.

\section{Acknowledgment}

The corresponding author would like to acknowledge the technical help rendered for the Hall measurements by E. I. Anila and S. Davassiya of Opto-electronic lab, Department of Physics, Union Christian College, Aluva for the PL measurements.

\section{References}

1. K. Paulraj, S. Ramaswamy, A. M. S. Arulanantham, S. Valanarasu, M. Shkir, V. Ganesh, S. AlFaify, H. S. Kim, and A. Kathalingam, J. Mater. Sci.: Mater. Electron. 30, 18858 (2019). https://doi.org/10.1007/s10854-019-02242-8

2. A. Hussain and A. Rahman, Mater. Sci. Semiconductor Process. 16, 1918 (2013). https://doi.org/10.1016/j.mssp.2013.07.027

3. B. Touati, A. Gassoumi, C. Guasch, and N. K. Turki, Mater. Sci. Semiconductor Process 67, 20 (2017). https://doi.org/10.1016/j.mssp.2017.05.004 
4. A. B. Rohom, P. U. Londhe, P. R. Jadhav, G. R. Bhand, and N. B. Chaure, J. Mater. Sci.: Mater. Electron. 28, 17107 (2017). https://doi.org/10.1007/s10854-017-7637-4

5. L. Yuan, H. Michaels, R. Roy, M. Johansson, V. Öberg, A. Andruszkiewicz, X. Zhang, M. Freitag, and E. M. J. Johansson, ACS Appl. Energy Mater. 3, 3157 (2020). https://doi.org/10.1021/acsaem.0c00030

6. C. L. Johnson and J.W. Schwank, Sensors Actuators B 20, 55 (1994). https://doi.org/10.1016/0925-4005(93)01162-W

7. George F. Fine, Leon M. Cavanagh, A. Afonja, and R. Binions, Sensors 10, 5469 (2010). https://doi.org/10.3390/s100605469

8. H. Karami, M. Ghasemi, and S. Matini, Int. J. Electrochem. Sci. 8, 11661 (2013).

9. V. V. Burungale, R. S. Devan, and S. A. Pawar, Mater. Sci. -Poland 34, 204 (2016). https://doi.org/10.1515/msp-2016-0001

10. K. N. C. Kumar, S. K. K. Basha, and G. S. Muhammad, Int. J. Chem. Technol. Res. 7, 2257 (2014).

11. H. Soetedjo, B. Siswanto, I. Aziz, and S. Sudjatmoko, J. Non-Oxide Glasses 9, 55 (2017).

12. M. G. Faraj, Am. J. Condensed Matter Phys. 5, 51 (2015).

13. D. K. Sonavane, S. K. Jare, R. V. Kathare, R. N. Bulakhe, and J. -J. Shim, Mater. Today: Proceed. 5, 7743 (2018). https://doi.org/10.1016/j.matpr.2017.11.451

14. J. J. Valenzuela-J'auregui, R. Ram'irez-Bon, A. Mendoza-Galva'n, M. Sotelo-Lerma, Thin Solid Films 441, 104 (2003). https://doi.org/10.1016/S0040-6090(03)00908-8

15. B. Abdallah, A. Ismail, H. Kashoua, and W. Zetoun, J. Nanomater. 2018, ID 1826959 (2018). https://doi.org/10.1155/2018/1826959

16. E. Barrios-Salgado, Y. Rodr-guez-Lazcano, J. P. Pérez-Orozco, J. Colin, P. Altuzar, J. Campos, and D. Quesada, Adv. Condensed Matter Phys. 2019, ID 5960587 (2019). https://doi.org/10.1155/2019/5960587

17. M. M. Abbas, A. Ab-M. Shehab, N. -A. Hassan, A. -K. Al-Samuraee, Thin Solid Films 519, 4917 (2011). https://doi.org/10.1016/S0040-6090(03)00908-8

18. N. H. Sheeba, S. C. Vattappalam, G. S Okram, V. Sharma, P. V. Sreenivasan, S. Mathew, and R. R. Philip, Mater. Res. Bull. 93, 130 (2017). https://doi.org/10.1016/j.materresbull.2017.04.021

19. B. Abdallah, R. Hussein, N. AlKafri, and W. Zetoun, Iran. J. Sci. Technol., Transact. A: Sci. 43, 1371 (2019). https://doi.org/10.1007/s40995-019-00698-1

20. F. Solis-Pomar, A. F. Cruz, JL Menchaca, MF Meléndrez and E. Pérez-Tijerina, Mater. Res. Express 5 (2018) ID 106403. https://doi.org/10.1088/2053-1591/aadac0

21. T. Tohidi and K. Jamshidi-Ghaleh, Appl. Phys. A 118, 1 (2014). https://doi.org/10.1007/s00339-014-8823-3

22. A. N. Fouda, M. Marzook, H. M. Abd El-Khalek, S. Ahmed, E. A. Eid, and A. B. El Basaty, Silicon 9, 809 (2015). https://doi.org/10.1007/s12633-015-9399-Z

23. S. Seghaier, N. Kamouna, R. Brini, and A. B. Amara, Mater. Chem. Phys. 97, 71 (2006). https://doi.org/10.1016/i.matchemphys.2005.07.061

24. F. Khatun, M. A. Gafur, M. S. Ali, M. S. Islam, and M. A. R. Sarker, J. Sci. Res. 6, 217 (2014). https://doi.org/10.3329/jsr.v6i2.17900

25. M. P. Sarma and G. Wary, Int. Lett. Chem. Phys. Astronomy 74, 22 (2017). https://doi.org/10.18052/www.scipress.com/ILCPA.74.22

26. N. Choudhury and B. K. Sarma, Bull. Mater. Sci. 32, 43 (2009). https://doi.org/10.1007/s12034-009-0007-y

27. J. Qiu, B. Weng, L. Zhao, C. Chang, Z. Shi, X. Li, H. K. Kim and Y. H. Hwang, J. Nanomater. 2014, ID 281461 (2014). http://dx.doi.org/10.1155/2014/281461

28. G. Bakiyaraj and R. Dhanasekaran, Appl. Nanosci. 3, 125 (2013). https://doi.org/10.1007/s13204-012-0075-y

29. A. Beggas, Z. Becer, R. Ahmim, and M. S. Aida, Defect Diffus. Forum 397, 125 (2019). https://doi.org/10.4028/www.scientific.net/DDF.397.125 
30. S. Rajathi, K. Kirubavathi, K. Selvaraju, J. Taibah Univ. Sci. 11, 1296 (2017). https://doi.org/10.1016/j.jtusci.2017.05.001

31. L. R. Singh, A. N. Singh, and S. B. Singh, Int. J. Lumines. Applicat. 5, 76 (2015).

32. K. V. Khot, S. S. Mali, N. B. Pawar, R. M. Mane, V. V. Kondalkar, V. B. Ghanwat, P. S. Patil, C. K. Hong, J. H. Kim, J. Heo, and P. N. Bhosale, J. Mater. Sci.: Mater. Electron. 25, 3762 (2014). https://doi.org/10.1007/s10854-014-2087-8

33. F. Gode, O. Baglayan, and E. Guneri, Chalcogenide Letts. 12, 519 (2015).

34. S. Thirumavalavana, K. Mani, and S. S. Sagadevan, J. Nano- Electron. Phys. 7, ID 04024 (2015).

35. M. V. Frischbier, H. F. Wardenga, M. Weidner, O. Bierwagen, J. Jia, Y. Shigesato, and A. Klein, Thin Solid Films 614, 62 (2016). https://doi.org/10.1016/j.tsf.2016.03.022 